\title{
Bedaquiline and multidrug-resistant tuberculosis: a systematic and critical analysis of the evidence
}

\author{
Emanuele Pontali ${ }^{1,5}$, Giovanni Sotgiu ${ }^{2,5}$, Lia D’Ambrosio ${ }^{3,4}$, Rosella Centis ${ }^{3}$ and \\ Giovanni Battista Migliori ${ }^{3}$
}

Affiliations: ${ }^{1}$ Dept of Infectious Diseases, Galliera Hospital, Genova, Italy. ${ }^{2}$ Clinical Epidemiology and Medical Statistics Unit, Dept of Biomedical Sciences - University of Sassari - Research, Medical Education and Professional Development Unit, AOU Sassari, Sassari, Italy. ${ }^{3}$ WHO Collaborating Centre for TB and Lung Diseases, Fondazione S. Maugeri, Care and Research Institute, Tradate, Italy. ${ }^{4}$ Public Health Consulting Group, Lugano, Switzerland. ${ }^{5}$ Both authors contributed equally.

Correspondence: Giovanni Battista Migliori, WHO Collaborating Centre for TB and Lung Diseases, Fondazione S. Maugeri, Care and Research Institute, via Roncaccio 16, 21049 Tradate, Italy.

E-mail: giovannibattista.miglioriafsm.it

$@$ ERSpublications

Systematic review of the available scientific evidence on the role of bedaquiline in new effective M/XDR-TB regimens http://ow.ly/V68ZF

The importance of adequately managing multidrug-resistant (MDR) and extensively drug-resistant (XDR) tuberculosis (TB) cases for TB control and elimination are underlined in the new World Health Organization (WHO) "End TB Strategy" $[1,2]$ as part of pillar one (integrated, patient-centred care and prevention; element 2: treatment of all people with TB including drug-resistant TB, and patient support) and in the recently published "Framework towards TB elimination in low incidence countries" in its priority action 5 (optimise the prevention and care of drug-resistant TB) and the related background documents [3-5]. Furthermore, both in the End TB Strategy (pillar 3: intensified research and innovation) and in the Framework towards TB elimination in low incidence countries (priority action 7: invest in research and new tools) the need for new anti-TB drugs is strongly emphasised $[1,3,6]$. The reasons why new anti-TB drugs are needed are rather obvious if you look closely at the dimensions of the MDR-TB epidemic and the treatment successes achieved so far.

Out of the 480000 MDR-TB cases estimated by WHO to have occurred in 2014, only 123000 (one quarter) have been diagnosed and notified [1]. Overall, 3.3\% of new and 20\% of retreatment cases harbour MDR-TB resistant strains of Mycobacterium tuberculosis, of whom $9.7 \%$ are proven to be XDR-TB [1]. The country with the highest prevalence of MDR-TB cases is Belarus (34\% in new and $69 \%$ in retreatment cases), where $29 \%$ of the cases are reported to be XDR-TB [1, 7].

Treatment of MDR-TB and XDR-TB has proven, so far, to be long, expensive and difficult-to-manage, and unfortunately, its outcomes are suboptimal in most cohorts $[8,9]$. Although XDR-TB cases actually represent a relatively small proportion of all MDR-TB cases (9\%), their treatment and management are significantly more challenging both for clinicians and national programmes [1]. Globally, treatment success of MDR-TB cases in the 2012 cohort was 50\% (16\% died, 16\% were lost to follow-up, 10\% failed, and $8 \%$ had no outcome information). Among the cases with a resistance pattern beyond XDR-TB the proportion of treatment success is unfortunately as low as $20 \%$, with $49 \%$ failure and death $[8,10]$.

The design of an effective regimen to treat MDR- and XDR-TB is based on the stepwise use of second-line TB drugs whose choice needs to be guided by drug susceptibility testing (DST) [11-13]. Unfortunately, at the programmatic level neither the drugs needed nor the specific DST to test them are always available

Received: Nov 132015 | Accepted: Nov 162015

Conflict of interest: Disclosures can be found alongside the online version of this article at erj.ersjournals.com

Copyright OERS 2016 
[11-13]. Furthermore, the possibility of combining second-line drugs to design the best possible regimen is often affected by a number of significant adverse events, which negatively affect adherence to treatment $[14,15]$.

During the past few years new drugs to treat MDR/XDR-TB have been developed following trials and, given their initial (although incomplete) efficacy data, they have received provisional approval while additional registration trials are still ongoing $[16,17]$. The updated pipeline of new drugs is reported in figure $1[1]$.

Although more is now known about the efficacy and tolerability of linezolid [18-25] and interest has been recently raised by the possibility of using other re-proposed compounds (carbapenems [26-28], sulphonamides [29, 30], and mefloquine [31], among others), the new anti-TB drugs delamanid [32] and bedaquiline are particularly promising [33-35].

The European Respiratory Journal (ERJ) has recently published several contributions related to the compassionate use of bedaquiline $[36,37]$ and the delamanid compassionate programme based on the European Respiratory Society (ERS)/WHO TB Consilium [38-45]. To better understand the role of bedaquiline in new regimens for the future we systematically reviewed the scientific evidence available on this drug.

Using the search engine PubMed the key words bedaquiline and efficacy/effectiveness were used to retrieve post-marketing studies describing the outcome of bedaquiline-containing regimens. Strict selection criteria, excluding case-reports and case-series, letters, editorials, and commentaries were adopted. No temporal ranges (until November 1, 2015) or language restrictions were included in the search. A total of 216 records were retrieved. Apart from less than 10 case-series/reports (including an interim cohort analysis on TB/HIV co-infected persons), no post-marketing experimental studies have been published, until now, to assess its effectiveness profile in the general population after the pre-marketing trials. The search results, which include the new study by Рyм et al. [46] are summarised in table 1 .

In this issue of the ERJ, PYM et al. [46] report results from the TMC207-C209 study. This study was a phase 2, multicentre, open-label, single-arm trial (TMC207-C209; ClinicalTrials.gov identifier: NCT00910871), conducted to confirm the safety and efficacy of bedaquiline. The trial enrolled 233 patients $(63.5 \%$ with MDR-TB, $18.9 \%$ with pre-XDR-TB, and $16.3 \%$ with XDR-TB). Most of them (87.1\%) had already received second-line drugs during previous treatment(s). In terms of efficacy, Pym et al. [46] observed that culture conversion at 24 weeks was durable and associated with a high likelihood of response at 120 weeks. Final culture conversion at 120 weeks was $72.2 \%$, with decreasing rates when resistance patterns worsened, i.e. $73.1 \%, 70.5 \%$ and $62.2 \%$ in MDR-TB, pre-XDR-TB and XDR-TB cases, respectively.

When considering safety, the most common adverse events were those typically observed during MDR-TB treatment. In addition, only six (2.6\%) subjects discontinued bedaquiline before week 24 due to adverse

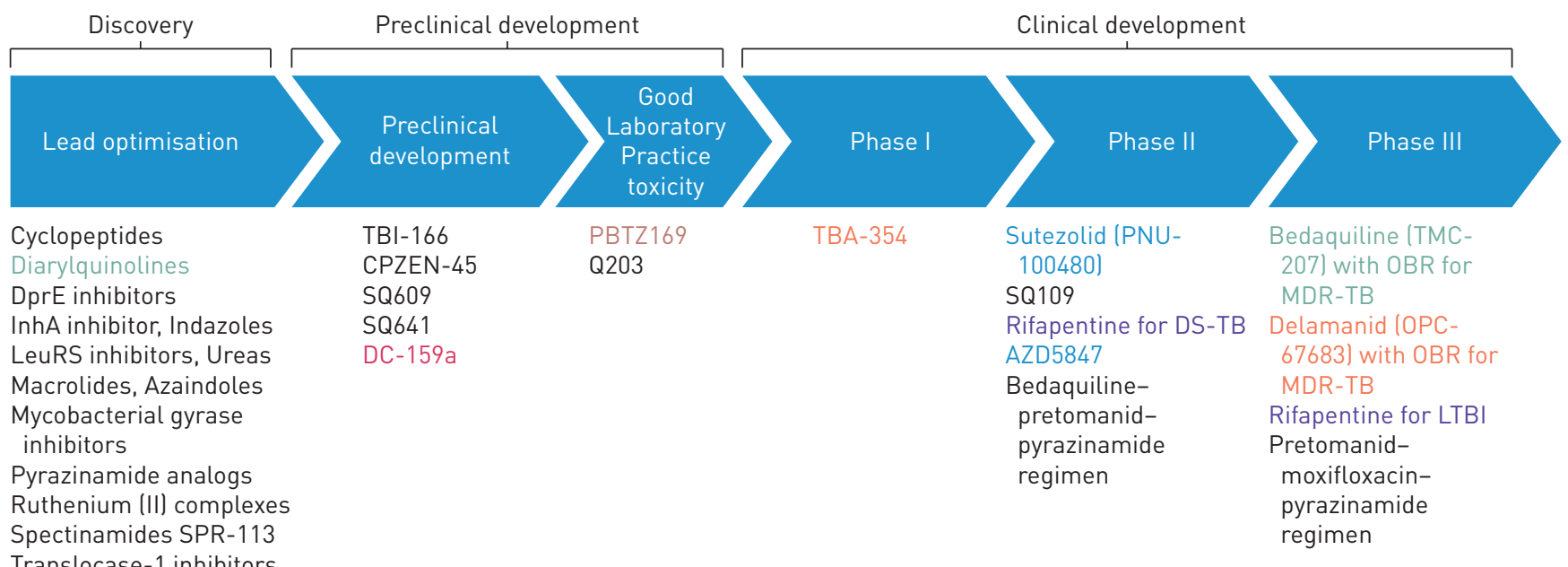

Chemical classes: fluoroquinolone, rifamycin, oxazolidinone, nitroimidazole, diarylquinoline, benzothiazinone

FIGURE 1 The development pipeline for new tuberculosis drugs in August 2015. Details of the projects listed can be found at http://www. newtbdrugs.org/pipeline.php and ongoing projects without a lead compound series identified can be viewed at http://www.newtbdrugs.org/ pipeline-discovery.php. OBR: optimised background regimen; DprE: decaprenylphosphoryl- $\beta$-D-ribose2'-epimerase; InhA: inhibin alpha; LeuRS: leucyl-tRNA synthetase; MDR-TB: multidrug-resistant tuberculosis; DS-TB: drug-susceptible tuberculosis; LTBI: latent tuberculosis infection. Reproduced from [1] with permission from the publisher. 
TABLE 1 Clinical studies on bedaquiline

\begin{tabular}{|c|c|c|c|c|c|c|c|}
\hline $\begin{array}{l}\text { First author } \\
\text { [ref.], year }\end{array}$ & Type of study & $\begin{array}{l}\text { Study } \\
\text { number }\end{array}$ & $\begin{array}{l}\text { Subjects taking } \\
\text { bedaquiline } n\end{array}$ & Efficacy findings & Tolerability findings & QTc effect & Notes \\
\hline $\begin{array}{l}\text { DIACON [52], } \\
2009\end{array}$ & $\begin{array}{l}\text { Phase Ilb, randomised, } \\
\text { multicentre, } \\
\text { double-blind, } \\
\text { placebo- } \\
\text { controlled study }\end{array}$ & $\begin{array}{l}\text { C208 } \\
\text { stage } 1\end{array}$ & 23 & $\begin{array}{l}\text { Bedaquiline reduced the } \\
\text { time to conversion to a } \\
\text { negative sputum culture } \\
\text { Bedaquiline increased the } \\
\text { proportion of patients } \\
\text { with conversion of } \\
\text { sputum culture }\end{array}$ & $\begin{array}{l}\text { Most AEs were mild to } \\
\text { moderate; only nausea } \\
\text { occurred significantly } \\
\text { more frequently in the } \\
\text { bedaquiline group }\end{array}$ & $\begin{array}{l}\text { QT interval prolongation was } \\
\text { observed in the bedaquiline } \\
\text { and placebo group (more } \\
\text { pronounced in the bedaquiline } \\
\text { group), with intergroup } \\
\text { differences ranging from } 1.0 \text { to } \\
10.8 \mathrm{~ms} \text { ( } p>0.05 \text { ) } \\
\text { None of the absolute values for } \\
\text { the corrected QT interval } \\
\text { exceeded } 500 \mathrm{~ms} \text {, and no } \\
\text { adverse events were associated } \\
\text { with ECG changes }\end{array}$ & \\
\hline $\begin{array}{l}\text { DIACON [53], } \\
2014\end{array}$ & $\begin{array}{l}\text { Phase Ilb, randomised, } \\
\text { multicentre, } \\
\text { double-blind, } \\
\text { placebo- } \\
\text { controlled study }\end{array}$ & $\begin{array}{l}\text { C208 } \\
\text { stage } 2\end{array}$ & 79 & $\begin{array}{l}\text { Bedaquiline reduced the } \\
\text { median time to culture } \\
\text { conversion from } \\
125 \text { days to } 83 \text { days }\end{array}$ & $\begin{array}{l}\text { Bedaquiline had similar } \\
\text { rates of AEs, } \\
\text { treatment-related AEs, } \\
\text { and AEs leading to study } \\
\text { discontinuation than } \\
\text { placebo } \\
\text { The most frequent AEs } \\
\text { were nausea, arthralgia } \\
\text { and vomiting } \\
\text { The severity of most } \\
\text { adverse events was } \\
\text { grade } 1 \text { or } 2\end{array}$ & $\begin{array}{l}\text { At study week } 24 \text {, the mean } \\
\text { change from baseline in the } \\
\text { QTcF was an increase of } \\
15.4 \text { ms in the bedaquiline } \\
\text { group and an increase of } \\
3.3 \text { ms in the placebo group } \\
\text { (p<0.001) } \\
\text { After bedaquiline treatment } \\
\text { ended, the QTcF gradually } \\
\text { decreased, and the mean value } \\
\text { was similar to that in the } \\
\text { placebo group by study } \\
\text { week } 60\end{array}$ & \\
\hline $\begin{array}{l}\text { GuglieLmetti [58], } \\
2015\end{array}$ & $\begin{array}{l}\text { Retrospective } \\
\text { cohort study }\end{array}$ & & 35 & $\begin{array}{l}\text { Culture conversion rate } \\
\text { was } 97 \% \text { after } 6 \text { months } \\
\text { of therapy }\end{array}$ & $\begin{array}{l}\text { Mild liver enzyme elevation } \\
(\geqslant 2 \text {-fold from baseline) } \\
\text { was reported in } 14 \% \text { of } \\
\text { patients, and } a \geqslant 5 \text {-fold } \\
\text { increase occurred in two } \\
\text { additional patients }(6 \%) \\
\text { Confounding effect of } \\
\text { concomitant drugs was } \\
\text { mentioned }\end{array}$ & $\begin{array}{l}\text { QTc prolongation was greater in } \\
\text { individuals exposed to } \\
\text { bedaquiline and } \\
\text { fluoroquinolones, or } \\
\text { clofazimine }\end{array}$ & \\
\hline $\begin{array}{l}\text { NDJEKA [59], } \\
2015\end{array}$ & $\begin{array}{l}\text { Interim } \\
\quad \text { cohort analysis }\end{array}$ & & $91\left(54 \mathrm{HIV}^{+}\right)$ & $\begin{array}{l}\text { In total, } 48(76 \%) \text { out of } 63 \\
\text { patients with } 6 \text { months } \\
\text { of follow-up either } \\
\text { achieved culture } \\
\text { conversion or remained } \\
\text { culture-negative } \\
6 \text { months after initiation } \\
\text { of bedaquiline }\end{array}$ & Good profile & $\begin{array}{l}\text { Clofazimine use and not HIV } \\
\text { infection was associated with } \\
\text { QTc increase }\end{array}$ & $\begin{array}{l}\text { ART based on } \\
\text { either } \\
\text { lopinavir/ } \\
\text { ritonavir or } \\
\text { nevirapine }\end{array}$ \\
\hline
\end{tabular}




\begin{tabular}{|c|c|c|c|c|c|c|c|}
\hline $\begin{array}{l}\text { First author } \\
\text { [ref.], year }\end{array}$ & Type of study & $\begin{array}{l}\text { Study } \\
\text { number }\end{array}$ & $\begin{array}{l}\text { Subjects taking } \\
\text { bedaquiline } n\end{array}$ & Efficacy findings & Tolerability findings & QTc effect & Notes \\
\hline $\begin{array}{l}\text { Pyм [46], } \\
2015\end{array}$ & $\begin{array}{l}\text { Phase 2, } \\
\text { multicentre, } \\
\text { multinational, } \\
\text { open-label, } \\
\text { noncomparative, } \\
\text { single-arm trial }\end{array}$ & $\begin{array}{l}\text { C209, } \\
\text { NCT00910871 }\end{array}$ & 233 & $\begin{array}{l}\text { Culture conversion was } \\
72.2 \% \text { at } 120 \text { weeks, and } \\
73.1 \%, 70.5 \% \text { and } 62.2 \% \\
\text { in MDR-TB, pre-XDR-TB } \\
\text { and XDR-TB patients, } \\
\text { respectively }\end{array}$ & $\begin{array}{l}\text { The commonest AEs were } \\
\text { similar to those } \\
\text { generally reported in } \\
\text { MDR-TB treatment } \\
\text { cohorts; most were } \\
\text { grade } 1 \text { or } 2 \\
\text { Hyperuricaemia and } \\
\text { increased aspartate } \\
\text { aminotransferase were } \\
\text { the most frequent grade } \\
\geqslant 3 \text { AEs } \\
\text { The incidence of AEs was } \\
\text { highest during the first } \\
12 \text { weeks } \\
\text { Serious AEs were reported } \\
\text { in } 47 \text { (20.2\%) patients: } \\
\text { respiratory infections/ } \\
\text { disorders were the most } \\
\text { common }\end{array}$ & $\begin{array}{l}\text { Prolongation of the QTcF interval } \\
\text { was reported infrequently } \\
\text { Two patients had an increase in } \\
\text { QTcF interval }>500 \text { ms; they } \\
\text { were both taking clofazimine, } \\
\text { and one had concurrent } \\
\text { hypokalaemia } \\
\text { No episodes of clinically } \\
\text { significant dysrhythmia were } \\
\text { reported }\end{array}$ & $\begin{array}{l}\text { Two deaths } \\
\text { were } \\
\text { considered } \\
\text { doubtfully } \\
\text { related to } \\
\text { bedaquiline }\end{array}$ \\
\hline
\end{tabular}

AEs: adverse events; QT interval: measure of the time between the start of the $Q$ wave and the end of the T wave in the heart's electrical cycle; QTc: QT interval corrected; QTcF: QT interval corrected by Fridericia's formula; MDR-TB: multidrug-resistant tuberculosis; XDR-TB: extensively drug-resistant tuberculosis. 
events or events related to the MDR-TB disease; discontinuations of the background regimen were more frequent. It has to be underscored that only two patients had clinically significant QTcF prolongation $(>500 \mathrm{~ms}$ ): one of them was in the bedaquiline arm, while both were prescribed clofazimine (which has known cardiotoxicity); one patient reported hypokalaemia. A significant mortality rate was observed (16 (6.9\%) deaths), although only three deaths occurred during bedaquiline treatment (one attributed to renal impairment and two to advanced TB). As noted elsewhere, the investigators had to go more in depth to evaluate specific causes of death and death-related risk factors [47]. The most frequent cause of death was $\mathrm{TB}$ or related-illnesses, and 10 out of 16 dead patients never achieved sputum smear and culture conversion. After revision of the causes of death of all patients, none of those who died had presented QTcF prolongation $>500 \mathrm{~ms}$ or had grade 3 or 4 liver adverse events (i.e. liver failure or an increase in liver function tests at levels more than 3 times the upper normal level).

\section{Bedaquiline: mechanism of action}

Bedaquiline is a novel compound (previously called TMC207 and R207910) belonging to the diarylquinoline group (figure 2). It was developed by Janssen Pharmaceuticals (Titusville, NJ, USA) [48]. This new anti-TB drug is the first in its class and presents a quinolinic central heterocyclic nucleus with alcohol and amine side chains responsible for its antimycobacterial activity. It is the only anti-TB drug that targets the energy metabolism of mycobacteria, inhibiting the mycobacterial ATP synthase [48, 49]. Bedaquiline is not active exclusively against drug-resistant $M$. tuberculosis isolates, but also against drug-susceptible strains. Its effective half-life is $>24 \mathrm{~h}$. [48].

Bedaquiline has been granted accelerated or conditional approval in the USA (2012) and Europe (2014) for use in MDR-TB, with interim guidance for its use provided by WHO [46, 50].

\section{The trials}

Initially a dose-finding study was carried out to investigate the early bactericidal activity, safety, tolerability and pharmacokinetics of bedaquiline [51]. Subsequently, the phase II C208 trial focusing on MDR-TB enrolled 47 patients that were randomly assigned to either placebo or bedaquiline [52]. A higher culture conversion rate was observed among those exposed to bedaquiline. The second stage of the same study (C208 stage 2) was a Phase IIb, randomised, multicentre double-blind, placebo-controlled study that involved 160 subjects [53]. A significant reduction in the time of sputum smear and culture conversion among those treated with bedaquiline was noted.

\section{Steps for programmatic introduction}

The introduction of bedaquiline for the treatment of drug-resistant TB in a new country usually precedes the "standard regulatory registration". It can occur through a number of alternative or complementary mechanisms [54-57].

FIGURE 2 The molecular structure of bedaquiline.

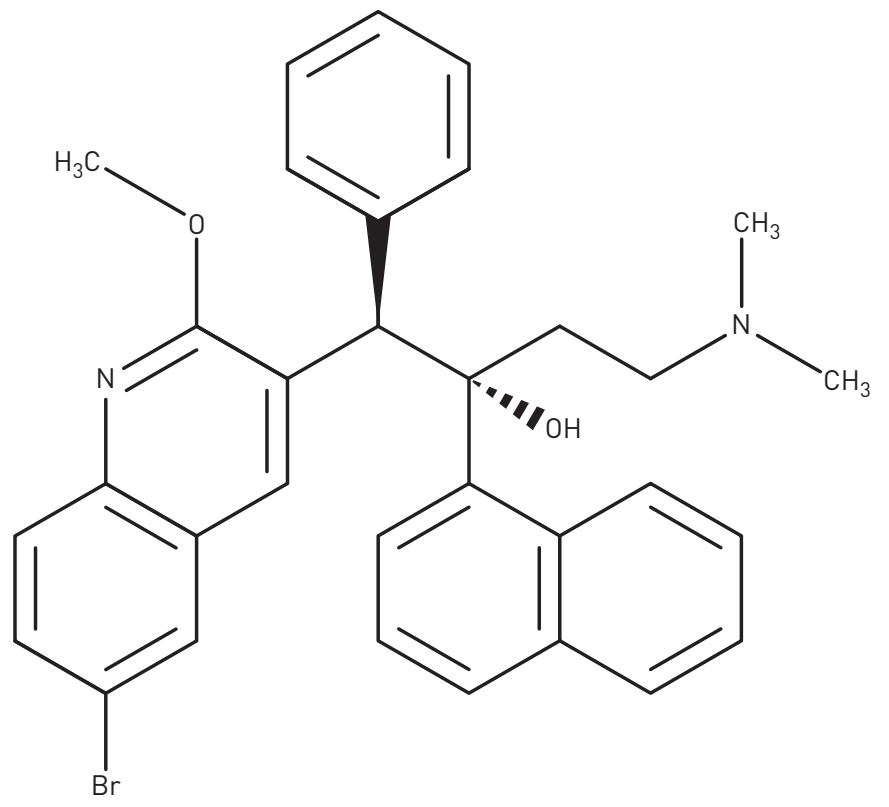


- Compassionate use, managed through international programmes, is either a manufacturer-initiated or a donor-led initiative. This mechanism lasts until the manufacturer submits a registration file and the local authorities allow a temporary registration, or until an expanded access programme is started.

- Expanded access programmes are regulated programmes providing the drug to a larger population, but still in a restricted way. Several conditions usually have to be met by the prescribing centres requesting the drugs and patient selection should follow specific rules. This lasts until the programme is completed (if a maximum number of treatments have been scheduled) or until the drug is finally registered.

- Temporary registration allows prescription by designated specialised clinical centres, but the drug is available in the country and it is reimbursable by local health authorities or by health insurance. During this phase further studies are conducted to assess efficacy and safety of the drug. In addition, pharmacovigilance is in place locally to identify potentially as yet unrecognised adverse events early.

\section{Open issues}

\section{Safety and tolerability}

The most frequent adverse drug reactions (i.e. those observed in $>10 \%$ of patients) during treatment with bedaquiline in the controlled trials were nausea, arthralgia and headache. Nevertheless, two key issues related to safety and tolerability remain open, and only additional data, such as those reported in this issue of the ERJ, will provide clarity on these issues [53].

The first issue is the increased risk of death reported in the bedaquiline treatment group (nine (11.4\%) out of 79 ) compared with the placebo treatment group (two (2.5\%) out of 81 ) in one of the studies based on the 120-week visit window [53]. This reported imbalance in deaths is still unexplained, and was not confirmed in the subsequent trials $[46,58,59]$.

The second issue is the QTc prolongation. In the first studies the QT increase from baseline in the bedaquiline group persisted even after the drug was discontinued. In addition, co-administration of bedaquiline and drugs causing QTc prolongation (e.g. fluoroquinolones and clofazimine) showed an additional effect in most studies [58-60]. Based on this argument WHO has not, so far, recommended the co-administration of bedaquiline and delamanid $[6,45,61]$. Actually, their introduction and (eventually) co-administration should occur following the WHO recommendations and having met specific criteria [45]. In fact, WHO recommend that the new drugs bedaquiline and delamanid are prescribed within sound TB control programmes within optimised background regimens designed as per WHO guidelines, at the right dosages, with a pharmacovigilance system in place, obtaining the patient's informed consent and implementing proper monitoring (i.e. monitoring of the QT interval, specifically for bedaquiline) [50, $61,62]$. Among the criteria proposed for co-administration in sporadic cases the most relevant ones are probably: the impossibility of otherwise designing an effective treatment regimen; the treatment centre is at least nationally qualified; informed consent is available; pharmacovigilance is in place; and the choice to prescribe both the new drugs together is supported by expert opinion [45].

\section{Resistance and drug susceptibility testing}

Resistance to bedaquiline might occur. A mutant atpE gene seems to be responsible for such resistance [63]. In the study by Рүм et al. [46] all 12 patients who had a post-baseline $\geqslant 4$-fold increase in bedaquiline minimal inhibitory concentration had mutations in Rv0678, a transcriptional repressor of the MmpS5-MmpL5 efflux pump [46, 48]. Recently, this novel efflux mechanism of resistance has been identified to be responsible for low-level resistance to bedaquiline and clofazimine $[48,64,65]$. Unfortunately, to date, an adequate protocol to test bedaquiline susceptibility has not been developed and agreed upon [34, 35].

\section{Paediatric use}

A few studies on bedaquiline have already been completed leading to its approval in adults only [46, 52, 53]. Thus, at present, if an additional active drug is absolutely needed to treat a child affected by MDR/XDR-TB, bedaquiline can be employed on a case-by-case basis only if an effective regimen cannot otherwise be constructed [66].

A paediatric phase II, open-label, multicentre study has been planned and it should involve young subjects (0-18 years old) with confirmed or probable pulmonary MDR-TB to assess the pharmacokinetics of bedaquiline in combination with the background regimen (ClinicalTrials.gov identifier: NCT02354014).

\section{Conclusions}

Bedaquiline is a new and interesting drug for the treatment of MDR-TB and XDR-TB. New evidence suggests that tolerability is better than expected and the reported effect on the QT interval can be properly managed in specialised centres. 
In perspective, bedaquiline might be used in new effective regimens for the treatment of MDR/XDR-TB, which will not include rifampicin and isoniazid (the two drugs defining MDR-TB). This will (hopefully) allow treatment of both drug-susceptible and drug-resistant cases with the same regimen. Furthermore, in absence of any negative interactions between antiretrovirals and rifamycins, these new regimens will allow easier management of HIV co-infected individuals. Bedaquiline is also a candidate component of shortened regimens for MDR-TB treatment [67]. In fact, with the purpose of finding responses to the challenges posed by MDR-TB treatment, the International Union Against Tuberculosis and Lung Disease has partnered with the Medical Research Council Clinical Trials Unit at University College London to evaluate shortened treatment regimens for MDR-TB and, in the second phase of the study, bedaquiline has been included to test shorter regimens $[67,68]$. In addition, in order to favour access to bedaquiline and other new anti-TB drugs in developing countries, in 2014, the UNITAID International Drug Purchasing Facility with finance from Partners in Health (USA) launched a project aimed at treating 3200 MDR-TB patients with regimens that also include new anti-TB drugs over the following 4 years [69].

The issue of the possible combined use of delamanid and bedaquiline, currently not recommended by WHO $[45,50,61]$, needs further evidence to protect patients from potential adverse events related to the combination of the two new drugs in addition to that deriving from the drugs used in the background regimen. Possible criteria to be taken into consideration to guide further studies on this have been recently described [45].

Furthermore, the potential of bedaquiline to possibily treat latent TB infection might deserve attention in the future [70].

\section{References}

1 World Health Organization. Global Tuberculosis Report 2015. 20th Edn. Geneva, World Health Organization, 2015.

2 Sotgiu G, Mauch V, Migliori GB, et al. Evidence-based, agreed-upon health priorities to remedy the tuberculosis patient's economic disaster. Eur Respir J 2014; 43: 1563-1566.

3 Lönnroth K, Migliori GB, Abubakar I, et al. Towards tuberculosis elimination: an action framework for low-incidence countries. Eur Respir J 2015; 45: 928-952.

4 Diel R, Loddenkemper R, Zellweger JP, et al. Old ideas to innovate tuberculosis control: preventive treatment to achieve elimination. Eur Respir J 2013; 42: 785-801.

5 D'Ambrosio L, Dara M, Tadolini M, et al. Tuberculosis elimination: theory and practice in Europe. Eur Respir J 2014; 43: 1410-1420.

6 Migliori GB, Lienhardt C, Weyer K, et al. Ensuring rational introduction and responsible use of new TB tools: outcome of an ERS multisector consultation. Eur Respir J 2014; 44: 1412-1417.

7 Skrahina A, Hurevich H, Zalutskaya A, et al. Alarming levels of drug-resistant tuberculosis in Belarus: results of a survey in Minsk. Eur Respir J 2012; 39: 1425-1431.

8 Migliori GB, Sotgiu G, Gandhi NR, et al. Drug resistance beyond extensively drug-resistant tuberculosis: individual patient data meta-analysis. Eur Respir J 2013; 42: 169-179.

9 Ahuja SD, Ashkin D, Avendano M, et al. Multidrug resistant pulmonary tuberculosis treatment regimens and patient outcomes: an individual patient data meta-analysis of 9,153 patients. PLoS Med 2012; 9: e1001300.

10 Falzon D, Gandhi N, Migliori GB, et al. Resistance to fluoroquinolones and second-line injectable drugs: impact on multidrug-resistant TB outcomes. Eur Respir J 2013; 42: 156-168.

11 Pontali E, Matteelli A, Migliori GB. Drug resistant tuberculosis. Curr Opin Pulm Med 2013; 19: 266-272.

12 Falzon D, Jaramillo E, Schünemann HJ, et al. WHO guidelines for the programmatic management of drug-resistant tuberculosis: 2011 update. Eur Respir J 2011; 38: 516-528.

13 World Health Organization. Companion Handbook to the WHO Guidelines for the Programmatic Management of Drug-Resistant Tuberculosis. Document N. WHO/HTM/TB/2014.11. Geneva, World Health Organization, 2014.

14 Seddon JA, Godfrey-Faussett $\mathrm{P}$, Jacobs $\mathrm{K}$, et al. Hearing loss in patients on treatment for drug-resistant tuberculosis. Eur Respir J 2012; 40: 1277-1286.

15 Isaakidis $\mathrm{P}$, Varghese B, Mansoor $\mathrm{H}$, et al. Adverse events among HIV/MDR-TB co-infected patients receiving antiretroviral and second line anti-TB treatment in Mumbai, India. PLoS One 2012; 7: e40781.

16 Pontali E, Sotgiu G, Centis R, et al. Management of drug resistant TB in patients with HIV co-infection. Expert Opin Pharmacother 2015 [in press; DOI:10.1517/14656566.2015.1100169].

17 Esposito S, Bianchini S, Blasi F. Bedaquiline and delamanid in tuberculosis. Expert Opin Pharmacother 2015; 16: 2319-2330.

18 Migliori GB, Eker B, Richardson MD, et al. A retrospective TBNET assessment of linezolid safety, tolerability and efficacy in multidrug-resistant tuberculosis. Eur Respir J 2009; 34: 387-393.

19 Villar M, Sotgiu G, D’Ambrosio L, et al. Linezolid safety, tolerability and efficacy to treat multidrug- and extensively drug-resistant tuberculosis. Eur Respir J 2011; 38: 730-733.

20 De Lorenzo S, Centis R, D’Ambrosio L, et al. On linezolid efficacy and tolerability. Eur Respir J 2012; 39: 770-772.

21 Sotgiu G, Centis R, D'Ambrosio L, et al. Efficacy, safety and tolerability of linezolid containing regimens in treating MDR-TB and XDR-TB: systematic review and meta-analysis. Eur Respir J 2012; 40: 1430-1442.

22 Sotgiu G, Centis R, D'Ambrosio L, et al. Linezolid to treat extensively drug-resistant TB: retrospective data are confirmed by experimental evidence. Eur Respir J 2013; 42: 288-290.

23 Lee M, Lee J, Carroll MW, et al. Linezolid for treatment of chronic extensively drug-resistant tuberculosis. $N$ Engl J Med 2012; 367: 1508-1518. 
24 Sotgiu G, Centis R, D’Ambrosio L, et al. Low minimal inhibitory concentrations of linezolid against multidrug-resistant tuberculosis strains. Eur Respir J 2015; 45: 287-289.

25 Sotgiu G, Pontali E, Migliori GB. Linezolid to treat MDR-/XDR-tuberculosis: available evidence and future scenarios. Eur Respir J 2015; 45: 25-29.

26 De Lorenzo S, Alffenaar JW, Sotgiu G, et al. Efficacy and safety of meropenem-clavulanate added to linezolid-containing regimens in the treatment of MDR-/XDR-TB. Eur Respir J 2013; 41: 1386-1392.

27 Tiberi S, D’Ambrosio L, De Lorenzo S, et al. . Ertapenem in the treatment of multidrug-resistant tuberculosis: first clinical experience. Eur Respir J 2016; 47: 177-185.

28 Tiberi S, D'Ambrosio L, De Lorenzo S, et al. Tuberculosis elimination, patients' lives and rational use of new drugs: revisited. Eur Respir J 2015; 47: 664-667.

29 Alsaad N, Wilffert B, van Altena R, et al. Potential antimicrobial agents for the treatment of multidrug-resistant tuberculosis. Eur Respir J 2014; 43: 884-897.

30 Alsaad N, van Altena R, Pranger AD, et al. Evaluation of co-trimoxazole in the treatment of multidrug-resistant tuberculosis. Eur Respir J 2013; 42: 504-512.

31 Krieger D, Vesenbeckh S, Schönfeld N, et al. Mefloquine as a potential drug against multidrug-resistant tuberculosis. Eur Respir J 2015; 46: 1503-1505.

32 Sotgiu G, Pontali E, Centis R, et al. Delamanid (OPC-67683) for treatment of multi-drug-resistant tuberculosis. Expert Rev Anti Infect Ther 2015; 13: 305-315.

33 Caminero JA, Scardigli A. Classification of antituberculosis drugs: a new proposal based on the most recent evidence. Eur Respir J 2015; 46: 887-893.

34 Salfinger M, Migliori GB. Bedaquiline: 10 years later, the drug susceptibility testing protocol is still pending. Eur Respir J 2015; 45: 317-321.

35 Salfinger M, Migliori GB. Bedaquiline: finding the pores on the pot. Eur Respir J 2015; 46: 289-291.

36 Tiberi S, De Lorenzo S, Centis R, et al. Bedaquiline in MDR/XDR-TB cases: first experience on compassionate use. Eur Respir J 2014; 43: 289-292.

37 van Halsema C, Humphreys S, Bonington A. Extensively drug-resistant tuberculosis: early access to bedaquiline for a UK patient. Eur Respir J 2014; 43: 292-294.

38 Skripconoka V, Danilovits M, Pehme L, et al. Delamanid improves outcomes and reduces mortality in multidrug-resistant tuberculosis. Eur Respir J 2013; 41: 1393-1400.

39 Blasi F, Dara M, van der Werf MJ, et al. Supporting TB clinicians managing difficult cases: the ERS/WHO Consilium. Eur Respir J 2013; 41: 491-494.

40 D'Ambrosio L, Tadolini M, Dupasquier S, et al. ERS/WHO tuberculosis consilium: reporting of the initial 10 cases. Eur Respir J 2014; 43: 286-289.

41 Esposito S, D’Ambrosio L, Tadolini M, et al. ERS/WHO Tuberculosis Consilium assistance with extensively drug-resistant tuberculosis management in a child: case study of compassionate delamanid use. Eur Respir J 2014; 44: 811-815.

42 D'Ambrosio L, Tadolini M, Centis R, et al. Supporting clinical management of the difficult-to-treat TB cases: the ERS-WHO TB Consilium. Int J Infect Dis 2015; 32: 156-160.

43 D'Ambrosio L, Tadolini M, Centis R, et al. A new free-cost e-service supporting clinicians to manage their difficult-to-treat TB cases: the ERS-WHO TB Consilium. J Thorac Dis 2015; 7: 1080-1085.

44 Reed C, Mason L, Cox H, et al. Compassionate and optimum use of new tuberculosis drugs. Lancet Infect Dis; 15: 1131.

45 Matteelli A, D’Ambrosio L, Centis R, et al. Compassionate and optimum use of new tuberculosis drugs Lancet Infect Dis; 15: 1131-1132.

46 Pym AS, Diacon AH, Tang S-J, et al. Bedaquiline in the treatment of multidrug- and extensively drug-resistant tuberculosis. Eur Respir J 2016; 47: 564-574.

47 Pontali E, Centis R, D’Ambrosio L, et al. Monitoring predictors of mortality: a necessary action to reach TB elimination causes of death and death-related risk factors. Rev Port Pneumol 2015 [in press; DOI: 10.1016/j. rppnen.2015.10.007]

48 Andries K, Verhasselt P, Guillemont J, et al. A diarylquinoline drug active on the ATP synthase of Mycobacterium tuberculosis. Science 2005; 307: 223-227.

49 Koul A, Dendouga N, Vergauwen K, et al. Diarylquinolines target subunit c of mycobacterial ATP synthase. Nat Chem Biol 2007; 3: 323-324.

50 World Health Organization. The use of bedaquiline in the treatment of multidrug-resistant tuberculosis. Interim policy guidance. Geneva, World Health Organization, 2013.

51 Diacon AH, Dawson R, Von Groote-Bidlingmaier F, et al. Randomized dose-ranging study of the 14-day early bactericidal activity of bedaquiline (TMC207) in patients with sputum microscopy smear-positive pulmonary tuberculosis. Antimicrob Agents Chemother 2013; 57: 2199-2203.

52 Diacon AH, Pym A, Grobusch M, et al. The diarylquinoline TMC207 for multidrug-resistant tuberculosis. $N$ Engl J Med 2009; 360: 2397-2405.

53 Diacon AH, Pym A, Grobusch MP, et al. Multidrug-resistant tuberculosis and culture conversion with bedaquiline. N Engl J Med 2014; 371: 723-732.

54 Lienhardt C, Raviglione M, Spigelman M, et al. New drugs for the treatment of tuberculosis: needs, challenges, promise, and prospects for the future. J Infect Dis 2012; 205: Suppl. 2, S241-S249.

55 U.S. Food and Drug Administration. Expanded Access (Compassionate Use). www.fda.gov/NewsEvents/ PublicHealthFocus/ExpandedAccessCompassionateUse/ucm20080392.htm Date last accessed: November 12, 2015. Date last updated: November 19, 2015.

56 European Medicines Agency. Human medicines: regulatory information. www.ema.europa.eu/ema/index.jsp? curl=pages/regulation/landing/human_medicines_regulatory.jsp Date last accessed: November 12, 2015.

57 European Medicines Agency, Committee for medicinal products for human use (CHMP). Guideline on compassionate use of medicinal products, pursuant to article 83 of regulation (EC) No 726/20004. www.ema europa.eu/docs/en_GB/document_library/Regulatory_and_procedural_guideline/2009/10/WC500004075.pdf Date last accessed: November 12, 2015. Date last updated: July 19, 2007.

58 Guglielmetti L, Le Dû D, Jachym M, et al. Compassionate use of bedaquiline for the treatment of multidrug-resistant and extensively drug-resistant tuberculosis: interim analysis of a French cohort. Clin Infect Dis 2015; 60: 188-194. 
59 Ndjeka N, Conradie F, Schnippel K, et al. Treatment of drug-resistant tuberculosis with bedaquiline in a high HIV prevalence setting: an interim cohort analysis. Int J Tuberc Lung Dis 2015; 19: 979-985.

60 Annex I. Summary of product characteristics. Sirturo $100 \mathrm{mg}$ tablets. www.ema.europa.eu/docs/en_GB/document_ library/EPAR_-_Product_Information/human/002614/WC500163209.pdf Date last accessed: December 15, 2015.

61 World Health Organization. The use of delamanid in the treatment of multidrug-resistant tuberculosis. Interim policy guidance. Geneva, World Health Organization, 2014.

62 World Health Organization. Policy implementation package for new TB drug introduction. Geneva, World Health Organization, 2014.

63 Petrella S, Cambau E, Chauffour A, et al. Genetic basis for natural and acquired resistance to the diarylquinoline R207910 in mycobacteria. Antimicrob Agents Chemother 2006; 50: 2853-2856.

64 Hartkoorn RC, Uplekar S, Cole ST. Cross-resistance between clofazimine and bedaquiline through upregulation of MmpL5 in Mycobacterium tuberculosis. Antimicrob Agents Chemother 2014; 58: 2979-2981.

65 Gupta S, Cohen KA, Winglee K, et al. Efflux inhibition with verapamil potentiates bedaquiline in Mycobacterium tuberculosis. Antimicrob Agents Chemother 2014; 58: 574-576.

66 Centers for Disease Control and Prevention. Provisional CDC guidelines for the use and safety monitoring of bedaquiline fumarate (Sirturo) for the treatment of multidrug-resistant tuberculosis. www.cdc.gov/mmwr/preview/ mmwrhtml/rr6209a1.htm Date last accessed: November 12, 2015. Date late updated: October 25, 2013.

67 International Union Against Tuberculosis and Lung Disease. Current Trials: STREAM clinical trial to test first all-oral MDR-TB treatment regimen. www.theunion.org/what-we-do/research/clinical-trials Date last accessed: November 12, 2015

68 Nunn AJ, Rusen ID, Van Deun A, et al. Evaluation of a standardized treatment regimen of anti-tuberculosis drugs for patients with multi-drug-resistant tuberculosis (STREAM): study protocol for a randomized controlled trial. Trials 2014; 15: 353.

69 UNITAID. UNITAID Approves Grants of \$160 million. www.unitaid.org/en/resources/press-centre/releases/ 1352-unitaid-approves-grants-of-160-million Date last accessed: November 12, 2015. Date last updated: May, 6 2014.

70 Getahun H, Matteelli A, Abubakar I, et al. Management of latent Mycobacterium tuberculosis infection: WHO guidelines for low tuberculosis burden countries. Eur Respir J 2015; 46: 1563-1576. 